Received Date : 29-Sep-2016

Revised Date : 20-Nov-2016

Accepted Date : 23-Nov-2016

Article type : Meta-analysis

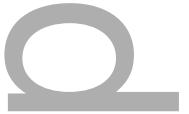

\title{
A systematic review and meta-analysis of prospective transition from major depression to bipolar disorder
}

\section{Authors:}

Aswin Ratheesh ${ }^{1,2}$, Christopher Davey ${ }^{1,2}$, Sarah Hetrick ${ }^{1,2}$, Mario Alvarez-Jimenez ${ }^{1,2}$, Catherine Voutier ${ }^{3}$, Andreas Bechdolf ${ }^{4,5}$, Patrick D McGorry ${ }^{1,2}$, Jan Scott ${ }^{6}$, Michael Berk $^{1,2,7,8}$, Susan M Cotton ${ }^{1,2}$

\section{Affiliations}

1 Orygen, The National Centre of Excellence in Youth Mental Health

2 Centre for Youth Mental Health, University of Melbourne

3 Royal Melbourne Hospital Library, Melbourne, Australia

4 Department of Psychiatry and Psychotherapy, University of Cologne, Germany,

5 Department of Psychiatry, Psychotherapy and Psychosomatics, Vivantes Hospital am Urban and Vivantes Hospital im Friedrichshain, Charite Universitätsmedizin, Berlin, Germany 6 University of Newcastle UK

7 Florey Institute of Neuroscience and Mental Health

8 Deakin University, Impact Strategic Research Centre

\section{Corresponding Author:}

Dr Aswin Ratheesh, Orygen Youth Health,

This is the author manuscript accepted for publication and has undergone full peer review but has not been through the copyediting, typesetting, pagination and proofreading process, which may lead to differences between this version and the $\underline{\text { Version of Record. Please cite this article as doi: 10.1111/acps.12686 }}$

This article is protected by copyright. All rights reserved 
35 Poplar road, Parkville, VIC 3052, Australia

email: aswinr@unimelb.edu.au

\title{
Declaration of Interest:
}

CD is supported by a National Health and Medical Research Council of Australia (NHMRC) Career Development Fellowship (1061757). PM currently receives research support from the NHMRC and the Colonial Foundation. He has also received grant funding from NARSAD and unrestricted research funding from Astra Zeneca, Eli Lilly, Janssen-Cilag, Pfizer, and Novartis, as well as honoraria for educational activities with Astra Zeneca, Eli Lilly, JanssenCilag, Pfizer, Bristol Myer Squibb, Roche and the Lundbeck Institute. JS has received UK grant funding from the Medical Research Council (including for projects on actigraphy and bipolar disorders) and from the Research for Patient Benefit programme (PB-PG-060916166). MB is supported by a NHMRC Senior Principal Research Fellowship (1059660) and receives grant funding from Deakin University, CRC for Mental Health, NIH, NHMRC, Stanley Medical Research Institute, CRE in Clinical Research, Meat and Livestock Australia, University of British Colombia, National Natural Science Foundation of China. MB has received personal fees from Janssen, Lundbeck, Astra Zeneca, Servier, Glax-Smithkline and Lilly Pharmaceuticals and has pending patents for NAC and related compounds. AR, CV, AB, SH, MA and SMC have no conflicts to declare.

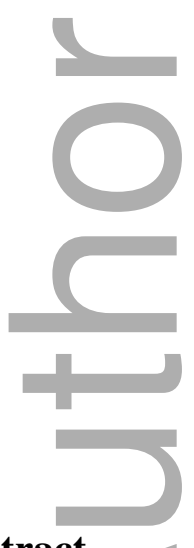

\begin{abstract}
Objective: Some people with major depressive disorder (MDD) may be at a pre-onset stage for Bipolar Disorder (BD), where early identification or prevention efforts may be feasible. We aimed to identify rates and characteristics predictive of transition to BD in prospective follow-up studies of people with MDD.
\end{abstract}


Methods: Using a systematic search strategy, we identified studies with a diagnostic ascertainment of MDD and BD of an adequate standard, and where the minimum length of follow-up was 6 months. We examined the incidence and point prevalence of $\mathrm{BD}$ and the pooled odds ratios $(O R)$ for baseline predictors.

Results: From 5554 unique publications, 56 were included. Nearly a quarter of adults $(22.5 \%)$ and adolescents with MDD and followed up for a mean length of 12-18 years developed $\mathrm{BD}$, with the greatest risk of transition being in the first 5 years. The meta-analysis identified that transition from MDD to BD was predicted by family history of BD $(O R=2.89$, 95\%CI:2.01-4.14, $N=7)$, earlier age of onset of depression $(g=-0.33, S E=0.05, N=6)$, and presence of psychotic symptoms $(O R=4.76,95 \% \mathrm{CI}: 1.79-12.66, N=5)$.

Conclusion: Participants with the identified risk factors merit closer observation and may benefit from prevention efforts, especially if outcomes broader than BD are considered.

\section{Funding: None}

Keywords: bipolar disorder, depression, meta-analysis, risk factors, affective disorders.

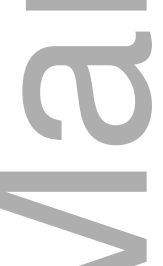

\section{Summations}

1. Nearly a quarter of MDD cases followed up for more than 12 years transitioned to $\mathrm{BD}$, with the greatest risk in the first 5 years of follow-up.

2. Consistent predictors of transition were a lower age of MDD onset, family history of $\mathrm{BD}$, and presence of psychotic symptoms in meta-analysis and subthreshold manic symptoms, in qualitative synthesis.

3. Use of samples with MDD enriched using such a profile may help identify subgroups where preventive interventions may be feasible, especially if outcomes broader than bipolar disorder are considered.

\section{Considerations}

1. The quality of included studies were highly variable and this may contribute to bias

2. Clinical and statistical heterogeneity limited meta-analysis of some risk factors 
3. Future cohort studies that have adequate statistical power to examine these risk factors may be necessary to clarify the relative predictive validity of risk factors, in terms of independence, additive effects, and/or magnitude of effect.

\section{Introduction}

Early intervention may help to reduce the impact of bipolar disorder (BD) (1). To achieve this, preventative efforts first require the identification of individuals at highest risk of onset of mania or hypomania. There are several potential high risk states, including where a person has: (i) a family history of BD (2); (ii) sub-threshold mood symptoms $(3,4)$; or (iii) major depression disorder (MDD) (3). From the perspective of prevention of BD, family history and subthreshold mood symptoms have been relatively well studied, while people with MDD have not been a major target of early identification efforts. Targeting MDD may hold some advantages compared to the other risk states. First, most people with BD (58-71\%) have depressive onset polarity (5). Second, MDD may represent a more proximal risk state for BD. For example, asymptomatic familial at-risk cohorts need to be followed up for significant lengths of time to allow for sufficient transitions (6). Thus, a key pragmatic question for early intervention is whether the likelihood of transition to BD from MDD occurs at a sufficient rate to justify screening and intervention. Additionally, factors that help improve the identification of those with a greater likelihood of transition to BD may be of direct relevance to clinicians providing care for people presenting with major depressive episodes.

While previous reviews have examined the development of BD in samples with depression, these have been unsystematic (7), limited to antidepressant associated switch (8) or in samples under the age of 18 (9). Importantly, variability in follow-up periods has not always been considered and is likely to impact on transition rate estimates. Thus, the aims of the study were to examine: (i) how likely transition was from MDD to BD; (ii) whether there was a peak risk period in which transitions occur; and (iii) whether there were distinctive profiles of individuals who transition from MDD to BD.

\section{Methods}

We examined the published literature on the rates and predictors of longitudinal transition to BD I or II among cohorts identified to have syndromal MDD at baseline that were followed up prospectively. The reporting of the systematic review conforms with the Preferred 
Reporting Items for Systematic Review and Meta-Analysis (10) (PRISMA) checklist (Supplementary Table 3).

Search Strategy: We constructed two strategies and searched citations of included studies or reviews to identify all relevant publications that met eligibility criteria for the review. The primary search strategy included the following terms in title and abstracts:

1. Mood disorders: Depressive disorder, Affective Disorders, Psychotic+, Bipolar

- Disorder (or Bipolar and related disorders) (in full texts) along with unipolar*, depressive (disorder* OR syndrome*) MDD, (severe OR endogenous OR neurotic) (depression* OR depressive), cyclothym*, labile, hypomani*, hypermani*, manic, mania*, bipolar, BP, BD, BPI, BPII, mood, affective, paraphren*, pre-bipolar

2. Study method: The terms conversion, evolv*, cycl*, shift*, switch*, progress*, predict*, emerg*, transition*, progress*, develop*, stability

These terms were searched in Medline, PsycINFO, and Embase (using the Ovid interface) and limited to articles published from 1 January 1979 until 16 September 2016. Bibliographies of reviews and original research articles were screened for relevant materials. Please see Supporting Information (online) for a full search algorithm.

\section{Eligibility Criteria}

We included:

1. articles published in English;

2. original research;

3. studies with paediatric, adolescent, and adult samples up to the age of 65 years. Samples required a baseline diagnosis of MDD using recognized diagnostic criteria, namely the Diagnostic and Statistical Manual for Mental Disorders $\left(3^{\text {rd }}\right.$ edition or later) or the International Classification of Diseases $\left(10^{\text {th }}\right.$ ed.; ICD-10; World Health Organization, 2010);

4. studies where the BD I or II diagnosis was made using diagnostic criteria from the $3^{\text {rd }}$ edition or later versions of the DSM (DSM-III), Research Diagnostic Criteria (RDC 'definite' for hypomania), or ICD-10;

5. studies with a minimum follow-up of 6 months;

6. studies that reported both rates and predictors of transitions.

We excluded:

1. studies of geriatric depression to reduce risks of inclusion of secondary organic mania (11); 
2. record linkage studies or studies using administrative datasets as these studies often have poorer reliability and sensitivity with regards to diagnostic ascertainment (particularly for BD II (12)) than studies where participants were individually interviewed for research purposes. Additionally, clinician diagnoses used in these registers are often significantly discordant from research diagnoses, and also differ between registries (13);

3. studies that did not report data on MDD cases separately at baseline and/or did not report the outcomes for MDD cases separately at follow-up. This included transdiagnostic or disease-free samples recruited to prospective birth cohort studies (14) and studies of high-risk families or offspring of parents with BD (15).

Study Selection: Identified articles were initially screened independently by AR and two other researchers (from SC, MA, SH and CD) to assess eligibility. Any uncertainties regarding eligibility were resolved via consensus.

\section{Data Extraction:}

Data were extracted from included studies in a systematic manner using a pre-designed extraction form (undertaken by AR). On the proforma the following information was recorded: (i) study design; (ii) country of origin; (iii) baseline sample size; (iv) diagnostic criteria that were employed at baseline and follow-up, assessment instruments used and the person undertaking the examination; (v) treatment setting; (vi) sample attrition rate; (vii) follow-up duration and reassessment time points; (viii) blinding of assessment at follow-up; (ix) whether efforts were made to exclude BD cases at baseline; (x) baseline characteristics including age, gender, depressive phenomenology and reported comorbidities, illness course, exclusion criteria, treatment characteristics; (xi) outcome of BD (and any BD sub-types), prevalence and number of cases at follow up; and (xii) predictors identified in individual studies, statistical methods for analyses, and reported effect sizes.

We aimed to examine the following group of predictive variables:

1. demographic features - age and gender

2. family history - family history of $\mathrm{BD}$, family history of affective disorders (including MDD or BD, where authors did not report the prevalence separately), presence of multi-generational family histories or a 'loaded affective pedigree'. A loaded family history was defined as the presence of 3 or more family members with a mood disorder and a multi-generational family history was defined as 3 generations of the family tree having at least one person with a mood disorder. 
3. course characteristics of MDD- age of onset of MDD, presence of recurrent MDD (defined as the presence of more than $1 \mathrm{MDE}$ ), presence of chronic MDE (defined as the persistence of MDE for more than 2 years)

4. symptom characteristics associated with baseline $M D D$ - presence of psychotic symptoms, presence of manic symptoms below the threshold for BD I or II, atypical symptoms of depression, and presence of specific symptoms such as guilt, irritability and somatic symptoms. Manic symptoms below the threshold of BD I or II could include BD NOS, (hypo)manic symptoms in the context of medication use (referred to as 'pharmacological hypomania'), as well as manic symptoms. Presence of psychotic symptoms could be examined only within the sub-sample of studies that did not select participants solely based on their diagnoses being one of MDD with psychosis.

5. comorbid disorders - presence of comorbid anxiety disorders; disruptive behaviour disorders (e.g., ADHD, conduct disorders); and personality disorders.

Heterogeneity in definition of baseline variables: To decrease clinical heterogeneity, only those variables defined in a similar manner across studies were pooled. For example, psychosis was combined with reports of 'delusions and hallucinations', but pharmacological hypomania was not combined with hypomanic symptoms. With respect to diagnostic heterogeneity, participants with baseline diagnoses of schizoaffective disorder (i.e., depressive type at baseline and manic type at follow-up) were excluded from the examination of BD rates. In line with DSM IV (16), the development of mixed episodes in cases with MDD were considered equivalent to manic episodes.

Data management of multiple outputs from individual cohorts: Data from multiple reports for the same cohorts were included provided that duplicate data were not included within any specific analysis. For example, among cohorts where rates of BD were reported at more than one follow-up time, data from each follow-up were included for quantification of rate of transition over time ensuring that data from each cohort did not appear more than once in each pooled analysis. Thus, for each pooled analysis, only independent datasets were included.

Definition of prepubertal studies: In line with previous meta-analyses (18), studies where the majority of the sample was described as prepubertal or where the mean baseline age of the sample was less than or equal to 12 years at baseline were considered to be prepubertal 
studies. These were analysed separately due to the possibility that prepubertal BD may have been diagnosed differently from adult-pattern BD (16).

Variables were included in a qualitative synthesis if more than one independent publication examined any association between the variable and BD. Variables were additionally included in a quantitative synthesis if three or more independent reports examined an association between that yariable and BD. Length of follow-up was used as a proxy measure of the time to the index episode of $\mathrm{BD}$, as this was the most consistent information available. In quantitative analysis, mean length of follow-up was utilized when this information was directly ayailable or could be extracted from the reported data.

Quality Assurance: Study quality was assessed using a purpose-built measure. This included items from the Newcastle Ottawa Scale (17) and the Strengthening the Reporting of Observational Studies in Epidemiology (STROBE) statement (18). The instrument covered the domains of overall study design, ascertainment of diagnoses, representativeness of the depressed sample at baseline, blinding on follow-up assessment, the rate of attrition of the sample and the risk of inclusion of subthreshold BD on follow-up (details in Supplementary Table 2).

Statistical Analyses: Analyses were conducted separately for prepubertal samples, and for adolescent and adult samples (the latter two groups were combined) using random effects models from the Comprehensive Meta-Analysis v2.0. The main outcomes for the metaanalytic component of the review were:

1. incidence of BD I or II expressed in events per 100 person years of follow-up; and

2. point prevalence of BD I or II expressed as a percentage;

3. pooled odds ratio $(O R)$ with $95 \%$ confidence intervals $(95 \% \mathrm{CI})$ for predictors of transition to $\mathrm{BD}$ I or II - we used the reported $O R$ or estimated them from prevalence data reported in studies.

Publication bias was examined by visual inspection of a funnel plot of logit event rate (prevalence of BD on follow-up) mapped against study precision and Egger's regression.

\section{Analyses of rates and predictors:}

Incidence: Within the first two years, incidence of BD in 100 person-years of follow-up was estimated. The person-years of follow-up were calculated by multiplying the mean duration of follow-up (in years) with the mean-population (number of persons) at risk during this 
period (19). The latter was derived using the intake sample size, the follow-up sample size and the transitions to BD during this time. This method was not used for analyses of later follow-ups due to the lack of adequate data on sample attrition compared to transition at various time points.

Point prevalence: Beyond the two-year follow-up point, transitions to BD were estimated as the point prevalence based on the identified number of persons who developed BD and the persons with MDD who were followed up to that time point (i.e., in the retained sample not the original sample).

Examination of the variance in point prevalence: Given the possible relationship between prevalence of $\mathrm{BD}$ and length of follow-up, and in the absence of survival analyses or individual patient data from the studies, prevalence rates were sub-grouped based on: (i) measures of central tendency including mean, median and mode; (ii) a visual examination of a scatterplot of the length of follow-up compared with point prevalence of BD at that length of follow-up (meta-regression); and (iii) percentile distribution of the length of follow-up in all post-pubertal studies (dividing studies into quartiles). The point prevalence was used to arrive at an approximate estimate of the prevalence of BD per year of follow-up (by dividing the prevalence at each time point by the length of years of follow-up). For examination of the variance in the transition rate over time, this prevalence rate per year of follow-up was correlated with the length of follow-up in years, using Spearman's rank correlation. This method was limited to examination of the variation of rates of transitions over time only, as this estimation does not account for the person-years followed up in each study and the variability over time. When the effect of length of follow-up on the point prevalence of BD could be minimized, subgroup analyses using moderators were conducted in order to examine for effects of categorical variables (such as recruitment of samples) describing groups of studies. Meta-regressions were utilized to examine for residual heterogeneity related to continuous variables such as age, gender distribution and study quality.

Analysis of predictors of transition to BD: Pooled ORs were estimated from prevalence of transition to BD in groups with or without the variable present, or when this was not available, then from univariate $O R$ s reported in the papers or available in communication with the authors. Subgroup analyses and meta-regressions were not possible as few predictors had sufficient studies in analyses of pooled $O R$ s.

Examination of heterogeneity: Statistical heterogeneity was tested using $I^{2}$ values $(20) . I^{2}$ is the ratio of true heterogeneity to the total variance observed across the observed effect 
estimates (21). Random effects analyses were used uniformly in all analyses due to the expectation of large clinical heterogeneity in the included studies due to which the assumptions of fixed effects were not considered to be met. Random effects analyses were also more likely to minimize the impact of very large or very small studies. When the $I^{2}$ values were moderate or high (defined as $>25 \%$ ) (20) using random effects models, the data were not pooled (21). Alternately, sensitivity analyses were conducted by excluding individual studies to examine models with lower statistical heterogeneity.

\section{Results}

---Insert Fig 1 about here---

\section{Included studies}

Of 5554 unique publications, full texts of 188 articles were screened and 56 of those met eligibility criteria (Figure 1). All studies provided qualitative data (Supplementary Table 1), while 35 were utilized for the analysis of rates of transition from MDD to BD, and 24 studies were included in qualitative or quantitative synthesis of predictors. Studies varied substantially in their design and quality (Supplementary Table 2). Most studies examined cohorts with MDD for a variety of outcomes and examined BD outcomes in post-hoc casecontrol designs. This meant that a) either all risk factors were not measured or b) studies were not powered to examine the baseline risk factors for their ability to predict transition to BD in univariate or multivariate models. There was no evidence of publication bias in a funnel plot of logit event rate plotted against study precision (Supplementary Figure 1) or according to Egger's test. The mean or median length of follow-up varied from 8 months to 18 years. The modal duration was 2 years and the mean length of follow-up was 5.87 years.

\section{Studies with adolescent and adult depression}

$\underline{\text { Rates of transition to BD from meta-analysis }}$

\section{1) Incidence of BD within 2 years of follow-up (Fig 2):}

The cumulative incidence of $\mathrm{BD}$ was 4.0 per 100 person-years of follow-up ( $S E=0.5$, $\left.Q=10.5, d f=10, I^{2}=4.42\right)$ (Figure 2) ( $\left.\mathrm{N}=11\right)$. One study was excluded because it added high statistical and clinical heterogeneity (22). This is reflected in the study's protocol that required multiple structured diagnostic assessments over a 12-month period and in the findings that $22.5 \%$ of those with unipolar MDD were re-diagnosed as BD II over this time and $11.8 \%$ of those with an initial diagnosis of BD II were re-diagnosed as having MDD over the 12-month period. 
---Insert Fig 2 about here---

\section{2) Rates of transition over time}

---Insert Fig 3 about here---

A random-effects meta-regression of the length of follow-up on rate of transition to BD indicated a significant positive relationship (Slope $=0.062, S E=0.03, Q=4.33, d f=1, p=0.038$, $T^{2}=0.62$ ). The scatterplot revealed a cluster of studies with follow-ups of (i) up to 2 years; (ii) between 2 and 6 years; (iii) between 6 and 12 years; and (iv) more than 12 years (Figure 3). The prevalence of transition to BD in studies with 12 to 18 years of mean follow-up was $22.5 \%$ (95\% CI: 15.8-31.1), and sub-group analysis indicated that studies with length of follow-up greater than 12 years had a significantly greater point prevalence (proportion) of BD [Supplementary Figure 2]. However, these studies did not differ in their point prevalence of $\mathrm{BD}$ when divided into subgroups at cut-points $(2.0 \mathrm{y}, 4.0 \mathrm{y}, 10.0 \mathrm{y})$ based on quartiles in sensitivity analyses. Please see Supplementary Figure 5 and footnotes for details of further examination of residual heterogeneity in the point prevalence of $\mathrm{BD}$. The prevalence rate per year of follow-up was strongly negatively correlated with the length of follow-up $\left(r_{s}=-0.57\right.$, $p<0.001, N=35$ ), and this result remained after excluding one outlier study in the early years of follow-up $\left(r_{s}=-0.54, p<0.001, N=34\right)$ in sensitivity analysis [Supplementary Figure 3].

\section{Findings from qualitative synthesis of rates:}

In the largest study with multiple follow-ups (21), the majority of transitions to BD II or BD I occurred in the first 4 and 8 years respectively. A further publication from the same dataset (22) indicated that the rate of transition to BD was $2.5 \%$ cases per year in the first 5 years and showed a rate of transition thereafter of approximately $0.5 \%$ per year. In the Zurich study (23) and the lowa 500 study (24), over $85 \%$ of transitions from MDD to BD occurred within 3-5 years of prospective follow-up.

Baseline predictors associated with transition to BD in meta-analysis:

\section{A) Gender}

Ten reports provided data on gender distribution, while seven provided homogeneous data that allowed meta-analysis. The $O R$ for transition to $\mathrm{BD}$ was non-significantly lower in females $\left(O R=0.74 ; 95 \%\right.$ CI of OR 0.48-1.13, $\left.\mathrm{Q}=5.84, \mathrm{Q} d f=6, I^{2}=0\right)$ (Figure 4); but only one study reported a significant association between male gender and transition (25). 
---Insert Fig 4 about here---

\section{B) Age of onset of depression}

Nine articles examined the association between age of onset of MDD and transition to BD (25-34). All studies except two $(31,34)$ identified a significant association between lower age of onset and higher rates of transition. Data from five articles were combined in a metaanalysis and the pooled Hedges $g$ of $-0.32\left(S E=0.05, Q=5.90, d f=5, I^{2}=15.3 \%\right)$ indicated a small-medium effect (Figure 5). Age at onset of MDD in cases that did develop BD was 4.8 years $(S E=0.52)$ earlier than age at onset of MDD in those who did not develop BD.

---Insert Fig 5 about here---

C) Family history variables

Among eight studies $(25,29,31,35-39)$, five identified a positive association between family history of BD and onset of BD, with a pooled $O R$ of 2.89 (95\% CI: 2.17-4.14) (Figure 4).

Four studies $(25,28,40,41)$ examined the association between a family history of affective disorders (MDD or BD) and transition to BD (Figure 4); one reported a significant association (25). At the same time, three studies and their pooled $O R$ failed to identify a significant association between family history of depression in the index cases and transition to BD (31, $34,42)$.

D) Presence of psychotic symptoms

Four of five studies reported a significant association between psychotic symptoms and later onset of $\mathrm{BD}(29,32,35,36,43)$, with a pooled $O R$ of 4.76 (95\% CI of $O R: 1.79-12.66$, $Q=5.23, d f=4, I^{2}=23.5$ ) (Figure 4).

E) Antidepressant use

Meta-analysis of data from four studies demonstrated a non-significant association [OR=1.5 (95\% CI of OR: 0.68-3.48)] between antidepressant use and transition to $\operatorname{BD}(29,38,44,45)$.

$\underline{\text { Baseline predictors of transition based on qualitative data }}$

A) Phenomenology and course of depression

Severity of depression $(30,35)$, guilt $(35,46,47)$, and mood lability $(48,49)$ coexistent with baseline MDD were associated with BD in two or three studies each. The relationship between recurrent MDD was inconsistent with studies identifying a significant association 
$(25,30,33,50)$ and others failing to do so $(34,42)$. The difference in reporting prevented meta-analysis. Suicidal ideation $(28,47)$, or attempts $(25,28,31)$ did not consistently predict transition. Chronicity of depression $(\geq 2$ years) $(32,36)$ and atypical features were inconsistently related to the transition to BD. One study (26) identified an association with 'hypersomnic-retarded' depression while later studies did not identify this association, in multivariate $(34,47,51)$ or univariate $(35,42)$ analysis.

\section{B) Subthreshold (hypo)manic features}

The presence of subthreshold hypomanic symptoms $(34,42,48)$ was associated with BD transition. The total number of baseline manic symptoms was predictive of later BD in two studies that also identified a dose-response relationship between the number of manic symptoms and transition to BD $(34,42)$. Antidepressant associated subthreshold hypomanic periods were associated with greater odds of transition in two studies $(26,52)$.

\section{C) Other comorbid disorders and symptoms}

Comorbid social phobia was associated with transition to BD in two multivariate analyses $(33,53)$, while the relationship between substance use disorders $(25,28,33,47)$ as well as generalized anxiety $(33,53)$ or anxiety disorders as a group $(34,47)$ and BD transition were inconsistent.

\section{D) Other family history variables}

Two studies $(35,36)$ identified significant associations between risk of developing BD and either a loaded family pedigree (with multiple affected family members) or family history of affective disorders spanning three generations.

\section{E) Other risk factors}

Child abuse (51) and the severity of childhood trauma (34) were associated with later transition to BD in multivariate analyses in two studies.

\section{Prevalence and predictors in prepubertal samples}

The cumulative transition rate to BD in four studies, with follow-ups ranging from 6 to 12 years, was $19.5 \%$ (95\% CI of $O R: 7.4-42.2, Q=3.08, d f=3, I^{2}=2.6$ ) (Supplementary Fig 4). Within prepubertal samples (54-58), the predictors of transition included family history (56), subthreshold BD (59) and comorbid disorders, such as ADHD (58).

\section{Discussion}


Our meta-analysis identified that four persons out of every 100 with MDD followed up for each year are likely to transition to BD in the first two years. Almost a quarter of those followed up for more than 12 years transitioned to BD. Qualitative synthesis suggested that the greatest risk of transition from MDD to $\mathrm{BD}$ is in the first 5 years after baseline assessment, and meta-analysis confirmed the finding of greater transitions in the early years of follow-up. The most consistent predictors of diagnostic change among post-pubertal samples with MDD in meta-analytic examination were family history of BD, earlier age of onset and presence of psychotic symptoms. Additionally, qualitative results suggested that subthreshold manic symptoms may be predictive of transition to BD.

Rates of transition: Within the first two years, the incidence of BD was many-times higher among samples with MDD compared with the general population (estimated to be 0.73 per 100 person years of follow-up) (60). Thus, MDD can be a precursor stage for BD, and could help identify persons at risk of mania or hypomania, especially in the early years of followup. Factors accounting for the increased transition rate in the first few years may include more intensive follow-up, greater participant retention, as well as pathogenic processes that first account for the depressive episode but continue to operate to produce a first episode of mania or hypomania shortly afterwards.

Predictors of transition: Family history of BD was one of the most commonly identified risk factors. The relationship between transition and family history of mood disorders may be confounded by two studies where the family history of BD may have increased the risk of transition $(25,35)$. The lack of relationship between a family history of depression and later $\mathrm{BD}$ indicates the relative specificity of family history of BD to predicting later BD in MDD samples. This is consistent with family history studies that have identified specificity in familial transmission of mania and depression (61). Identified predictive factors such as age of onset, psychotic symptoms, and recurrent MDD may represent independent vulnerabilities or subtypes of depression with greater disorder severity. Two studies $(35,53)$ identified a direct association between depression severity and later BD.

Antidepressant use without associated hypomania was not related to a greater risk of transition in our meta-analysis, potentially moderated by the impact of mood stabilizers. In one study (44), the group that later developed (hypo)mania was more likely to be taking mood-stabilizers even prior to their first (hypo)manic episode. Overall, the exclusion of shortterm follow-up studies ( $<6$ months) may have limited our ability to examine the risk of antidepressant associated mood switch. 


\section{Limitations}

The main limitation of the meta-analysis is quality of the included studies. Nearly all studies were case-control in design and there was substantial methodological and clinical heterogeneity with respect to cohort characteristics such as study design and sample size. This heterogeneity resulted in only a small number of studies contributing to predictor analyses, limiting the precision of the estimates of effect size for each predictor. Heterogeneity in reporting of data also limited the ability to examine the cumulative predictive properties of factors such as subthreshold manic symptoms. Among the sources of heterogeneity, differences in the baseline sample characteristics could be explored in the analyses of rates but not among that of predictors. Pooling of ORs for predictors with different lengths of follow-up may introduce bias, as ORs were reported at different time points. However, in the absence of individual participant-level data or survival curves for most studies, this method may be considered acceptable (62). In addition, there may be a possible low risk of publication bias due to search parameters and limitations (e.g. limitation of studies to those published in English language).

\section{Relevance for pre-onset identification and interventions}

Given a greater clustering of transition to $\mathrm{BD}$ in the first few years in individual studies and meta-analysis, follow-up and prevention efforts may be more effective in this time period. The value of combining risk factors in risk prediction approaches is suggested by an additive effect of predictive variables $(48,63)$, though this was not able to be explored in the metaanalytic component. Depressed persons who have an earlier onset, a family history of $\mathrm{BD}$, comorbid psychotic symptoms and/or subthreshold manic symptoms may be the most appropriate target group for EI. Alternately, this may have direct clinical relevance in considering the risks of transition for adults and youth presenting with depressive episodes in routine clinical care. Earlier interventions in such populations should consider the risk-benefit profiles of such interventions and thus less specific, but more benign interventions may be preferable in such earlier stages $(64,65)$. Consideration of diagnosis for such individuals may also be conceived in a cross-diagnostic staging perspective where such episodes of major depression may be considered to be at a pre-illness stage for a more severe stage of recurrent unipolar disorder or a different disorder such as BD or psychotic disorders.

Considering outcomes broader than $\mathrm{BD}$, such as severe psychotic disorders in a transdiagnostic prevention approach may be useful as some of these risk markers may be true for severe psychotic disorders as well. Future meta-analyses using trans-diagnostic outcomes or primary cohort studies of young people enriched using these risk factors may assist in refining risk stages for BD and psychoses. Given that MDD may herald the onset of a range of serious 
mental illnesses, as well as poor physical health and vocational outcomes, including multiple outcomes in prevention strategies is not only helpful but may even be necessary as statistical power may be limited in efforts for single disorder prevention (66).

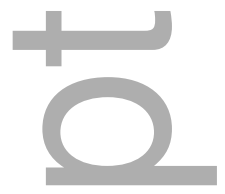

\section{References}

1. Berk M, Hallam K, Malhi GS, Henry L, Hasty M, Macneil C, et al. Evidence and implications for early intervention in bipolar disorder. Journal of mental health. 2010;19(2):113-26.

2. Duffy A. The early natural history of bipolar disorder: what we have learned from longitudinal high-risk research. Can J Psychiatry. 2010;55(8):477-85.

3. Bechdolf A, Ratheesh A, Wood SJ, Tecic T, Conus P, Nelson B, et al. Rationale and first results of developing at-risk (prodromal) criteria for bipolar disorder. Curr Pharm Des. 2012;18(4):358-75.

4. Howes OD, Lim S, Theologos G, Yung AR, Goodwin GM, McGuire P. A comprehensive review and model of putative prodromal features of bipolar affective disorder. Psychological medicine. 2010:1-11.

5. Etain B, Lajnef M, Bellivier F, Mathieu F, Raust A, Cochet B, et al. Clinical expression of bipolar disorder type I as a function of age and polarity at onset: convergent findings in samples from France and the United States. The Journal Of Clinical Psychiatry. 2012;73(4):e561-e6.

6. Egeland JA, Endicott J, Hostetter AM, Allen CR, Pauls DL, Shaw JA. A 16Year Prospective Study of Prodromal Features Prior to BPI Onset in Well Amish Children. J Affect Disord. 2012;142:186-92.

7. Baldessarini RJ, Faedda GL, Offidani E, Vazquez GH, Marangoni C, Serra G, et al. Antidepressant-associated mood-switching and transition from unipolar major depression to bipolar disorder: a review. J Affect Disord. 2013;148(1):129-35.

8. Tondo L, Vazquez G, Baldessarini RJ. Mania associated with antidepressant treatment: comprehensive meta-analytic review. Acta Psychiatr Scand.

2010;121(6):404-14. 
9. Uchida M, Serra G, Zayas L, Kenworthy T, Hughes B, Koster A, et al. Can manic switches be predicted in pediatric major depression? A systematic literature review. J Affect Disord. 2014;172C:300-6.

10. Moher D, Liberati A, Tetzlaff J, Altman DG, Group P. Preferred reporting items for systematic reviews and meta-analyses: the PRISMA statement. BMJ. 2009;339:b2535.

11. Tohen M, Shulman KI, Satlin A. First-episode mania in late life. Am J Psychiatry. 1994;151(1):130-2.

12. Ostergaard SD, Straszek S, Petrides G, Skadhede S, Jensen SO, MunkJorgensen $\mathrm{P}$, et al. Risk factors for conversion from unipolar psychotic depression to bipolar disorder. Bipolar Disord. 2014;16(2):180-9.

13. Sellgren C, Landen M, Lichtenstein P, Hultman CM, Langstrom N. Validity of bipolar disorder hospital discharge diagnoses: file review and multiple register linkage in Sweden. Acta Psychiatr Scand. 2011;124(6):447-53.

14. Kim-Cohen J, Caspi A, Moffitt TE, Harrington H, Milne BJ, Poulton R. Prior juvenile diagnoses in adults with mental disorder: developmental follow-back of a prospective-longitudinal cohort. Arch Gen Psychiatry. 2003;60(7):709-17.

15. Duffy A, Alda M, Hajek T, Sherry SB, Grof P. Early stages in the development of bipolar disorder. Journal of affective disorders. 2010;121(1-2):12735.

16. Parens E, Johnston J. Controversies concerning the diagnosis and treatment of bipolar disorder in children. Child Adolesc Psychiatry Ment Health. 2010;4:9.

17. Wells G SB, O'Connell J, Robertson J, et al. . The Newcastle-Ottawa Scale (NOS) for assessing the quality of nonrandomised studies in meta-analysis. 2011 [Available from: http://www.ohri.ca/programs/clinical_epidemiology/oxford.asp.

18. von Elm E, Altman DG, Egger M, Pocock SJ, Gotzsche PC, Vandenbroucke JP, et al. The Strengthening the Reporting of Observational Studies in Epidemiology (STROBE) statement: guidelines for reporting observational studies. Lancet. 2007;370(9596):1453-7.

19. Szklo M, \& Nieto, F. . Epidemiology: Beyond the Basics. 2nd ed. Boston: ones and Bartlett Publishers 2007.

20. Higgins JP, Thompson SG, Deeks JJ, Altman DG. Measuring inconsistency in meta-analyses. BMJ. 2003;327(7414):557-60. 
21. Borenstein M, Hedges LV, Higgins JPT, Rothstein HR. Introduction to MetaAnalysis. Chichester, UK.: John Wiley \& Sons, Ltd, ; 2009.

22. Gan Z, Diao F, Wei Q, Wu X, Cheng M, Guan N, et al. A predictive model for diagnosing bipolar disorder based on the clinical characteristics of major depressive episodes in Chinese population. Journal Of Affective Disorders. 2011;134(1-3):11925.

23. Angst J, Sellaro R, Stassen HH, Gamma A. Diagnostic conversion from depression to bipolar disorders: results of a long-term prospective study of hospital admissions. Journal of affective disorders. 2005;84(2-3):149-57.

24. Winokur G, Morrison J. The Iowa 500: Follow-up of 225 Depressives. The British Journal of Psychiatry. 1973;123(576):543-8.

25. Tondo L, Visioli C, Preti A, Baldessarini RJ. Bipolar disorders following initial depression: Modeling predictive clinical factors. J Affect Disord. 2014;167:449.

26. Akiskal HS, Walker P, Puzantian VR. Bipolar outcome in the course of depressive illness: Phenomenologic, familial, and pharmacologic predictors. Journal of Affective Disorders. 1983;5(2):115-28.

27. Beesdo K, Hofler M, Leibenluft E, Lieb R, Bauer M, Pfennig A. Mood episodes and mood disorders: patterns of incidence and conversion in the first three decades of life. Bipolar Disorders. 2009;11(6):637-49.

28. Bukh JD, Andersen PK, Kessing LV. Rates and predictors of remission, recurrence and conversion to bipolar disorder after the first lifetime episode of depression - a prospective 5-year follow-up study. Psychol Med. 2016:1-11.

29. Goldberg JF, Harrow M, Whiteside JE. Risk for bipolar illness in patients initially hospitalized for unipolar depression. Am J Psychiatry. 2001;158(8):1265-70. 30. Holma KM, Melartin TK, Holma IA, Isometsa ET. Predictors for switch from unipolar major depressive disorder to bipolar disorder type I or II: a 5-year prospective study. The Journal of clinical psychiatry. 2008;69(8):1267-75.

31. Ruggero CJ, Kotov R, Carlson GA, Tanenberg-Karant M, Gonzalez DA, Bromet EJ. Diagnostic consistency of major depression with psychosis across 10 years. Journal of Clinical Psychiatry. 2011;72(9):1207-13.

32. Coryell W, Endicott J, Maser JD, Keller MB. Long-term stability of polarity distinctions in the affective disorders. The American Journal of Psychiatry. 1995;152(3):385-90. 
33. Gilman SE, Dupuy JM, Perlis RH. Risks for the transition from major depressive disorder to bipolar disorder in the National Epidemiologic Survey on Alcohol and Related Conditions. The Journal Of Clinical Psychiatry. 2012;73(6):82936.

34. Boschloo L, Spijker AT, Hoencamp E, Kupka R, Nolen WA, Schoevers RA, et al. Predictors of the onset of manic symptoms and a (hypo)manic episode in patients with major depressive disorder. PLoS ONE [Electronic Resource]. 2014;9(9):e106871.

35. Strober M, Carlson G. Bipolar illness in adolescents with major depression: clinical, genetic, and psychopharmacologic predictors in a three- to four-year prospective follow-up investigation. Archives Of General Psychiatry. 1982;39(5):54955.

36. Akiskal HS, Walker P, Puzantian VR, King D, Rosenthal TL, Dranon M. Bipolar outcome in the course of depressive illness. Phenomenologic, familial, and pharmacologic predictors. Journal Of Affective Disorders. 1983;5(2):115-28.

37. Coryell W, Endicott J, Maser JD, Keller MB, Leon AC, Akiskal HS. Longterm stability of polarity distinctions in the affective disorders. The American journal of psychiatry. 1995;152(3):385-90.

38. Sharma V, Xie B, Campbell MK, Penava D, Hampson E, Mazmanian D, et al. A prospective study of diagnostic conversion of major depressive disorder to bipolar disorder in pregnancy and postpartum. Bipolar Disord. 2014;16(1):16-21.

39. Maj M, Pirozzi R, Magliano L, Fiorillo A, Bartoli L. Phenomenology and prognostic significance of delusions in major depressive disorder: a 10-year prospective follow-up study. The Journal Of Clinical Psychiatry. 2007;68(9):1411-7. 40. Paaren A, Bohman H, von Knorring L, Olsson G, von Knorring AL, Jonsson U. Early risk factors for adult bipolar disorder in adolescents with mood disorders: a 15-year follow-up of a community sample. BMC Psychiatry. 2014;14:363.

41. Li Z, Zhang C, Fan J, Yuan C, Huang J, Chen J, et al. Brain-derived neurotrophic factor levels and bipolar disorder in patients in their first depressive episode: 3-year prospective longitudinal study. Br J Psychiatry. 2014;205(1):29-35.

42. Fiedorowicz JG, Endicott J, Leon AC, Solomon DA, Keller MB, Coryell WH. Subthreshold hypomanic symptoms in progression from unipolar major depression to bipolar disorder. The American Journal Of Psychiatry. 2011;168(1):40-8. 
43. Johnson J, Horwath E, Weissman MM. The validity of major depression with psychotic features based on a community study. Arch Gen Psychiatry. 1991;48(12):1075-81.

44. DelBello MP, Carlson GA, Tohen M, Bromet EJ, Schwiers M, Strakowski SM. Rates and predictors of developing a manic or hypomanic episode 1 to 2 years following a first hospitalization for major depression with psychotic features. Journal Of Child And Adolescent Psychopharmacology. 2003;13(2):173-85.

45. Benvenuti A, Rucci P, Miniati M, Papasogli A, Fagiolini A, Cassano GB, et al. Treatment-emergent mania/hypomania in unipolar patients. Bipolar Disord. 2008;10(6):726-32.

46. Winokur G, Wesner R. From unipolar depression to bipolar illness: 29 who changed. Acta Psychiatrica Scandinavica. 1987;76(1):59-63.

47. Pfennig A, Ritter PS, Hofler M, Lieb R, Bauer M, Wittchen HU, et al. Symptom characteristics of depressive episodes prior to the onset of mania or hypomania. Acta Psychiatrica Scandinavica. 2016;133(3):196-204.

48. Salvatore P, Baldessarini RJ, Khalsa H-MK, Amore M, Di Vittorio C, Ferraro $\mathrm{G}$, et al. Predicting diagnostic change among patients diagnosed with first-episode DSM-IV-TR major depressive disorder with psychotic features. The Journal of Clinical Psychiatry. 2013;74(7):723-31.

49. Tohen M, Khalsa H-MK, Salvatore P, Vieta E, Ravichandran C, Baldessarini RJ. Two-year outcomes in first-episode psychotic depression the McLean-Harvard First-Episode Project. Journal Of Affective Disorders. 2012;136(1-2):1-8.

50. Beesdo K, Höfler M, Leibenluft E, Lieb R, Bauer M, Pfennig A. Mood episodes and mood disorders: patterns of incidence and conversion in the first three decades of life. Bipolar Disorders. 2009;11(6):637-49.

51. Gilman SE, Dupuy JM, Perlis RH. Risks for the transition from major depressive disorder to bipolar disorder in the National Epidemiologic Survey on Alcohol and Related Conditions. J Clin Psychiatry. 2012;73(6):829-36.

52. Strober M, Carlson G. Bipolar illness in adolescents with major depression: clinical, genetic, and psychopharmacologic predictors in a three- to four-year prospective follow-up investigation. Arch Gen Psychiatry. 1982;39(5):549-55. 53. Holma KM, Melartin TK, Holma IAK, Isometsä ET. Predictors for switch from unipolar major depressive disorder to bipolar disorder type I or II: a 5-year prospective study. The Journal Of Clinical Psychiatry. 2008;69(8):1267-75. 
54. Kovacs M, Akiskal HS, Gatsonis C, Parrone PL. Childhood-onset dysthymic disorder. Clinical features and prospective naturalistic outcome. Archives Of General Psychiatry. 1994;51(5):365-74.

55. Geller B, Fox LW, Clark KA. Rate and predictors of prepubertal bipolarity during follow-up of 6- to 12-year-old depressed children. Journal of the American Academy of Child and Adolescent Psychiatry [Internet]. 1994; 33(4):[461-8 pp.]. Available from: http://onlinelibrary.wiley.com/o/cochrane/clcentral/articles/198/CN00102198/frame.html.

56. Geller B, Zimerman B, Williams M, Bolhofner K, Craney JL. Bipolar disorder at prospective follow-up of adults who had prepubertal major depressive disorder. The American journal of psychiatry. 2001;158(1):125-7.

57. Weissman MM, Wolk S, Wickramaratne P, Goldstein RB, Adams P, Greenwald S, et al. Children with prepubertal-onset major depressive disorder and anxiety grown up. Arch Gen Psychiatry. 1999;56(9):794-801.

58. Biederman J, Petty CR, Byrne D, Wong P, Wozniak J, Faraone SV. Risk for switch from unipolar to bipolar disorder in youth with ADHD: a long term prospective controlled study. Journal Of Affective Disorders. 2009;119(1-3):16-21. 59. Biederman J, Wozniak J, Tarko L, Serra G, Hernandez M, McDermott K, et al. Re-examining the risk for switch from unipolar to bipolar major depressive disorder in youth with ADHD: A long term prospective longitudinal controlled study. Journal Of Affective Disorders. 2014;152-154:347-51.

60. Tijssen MJ, van Os J, Wittchen HU, Lieb R, Beesdo K, Mengelers R, et al. Evidence that bipolar disorder is the poor outcome fraction of a common developmental phenotype: an 8-year cohort study in young people. Psychological medicine. 2010;40(2):289-99.

61. Vandeleur CL, Merikangas KR, Strippoli MP, Castelao E, Preisig M. Specificity of psychosis, mania and major depression in a contemporary family study. Mol Psychiatry. 2014;19(2):209-13.

62. Ioannidis JP, Patsopoulos NA, Rothstein HR. Reasons or excuses for avoiding meta-analysis in forest plots. BMJ. 2008;336(7658):1413-5.

63. Tohen M, Khalsa H-MK, Salvatore P, Vieta E, Ravichandran C, Baldessarini RJ. Two-year outcomes in first-episode psychotic depression: The McLean-Harvard first-episode project. Journal of Affective Disorders. 2012;136(1-2):1-8. 
64. Scott J, Leboyer M, Hickie I, Berk M, Kapczinski F, Frank E, et al. Clinical staging in psychiatry: a cross-cutting model of diagnosis with heuristic and practical value. Br J Psychiatry. 2013;202:243-5.

65. Berk M, Conus P, Lucas N, Hallam K, Malhi GS, Dodd S, et al. Setting the stage: from prodrome to treatment resistance in bipolar disorder. Bipolar disorders. 2007;9(7):671-8.

66. Cuijpers P. Examining the effects of prevention programs on the incidence of new cases of mental disorders: the lack of statistical power. Am J Psychiatry. 2003;160(8):1385-91.

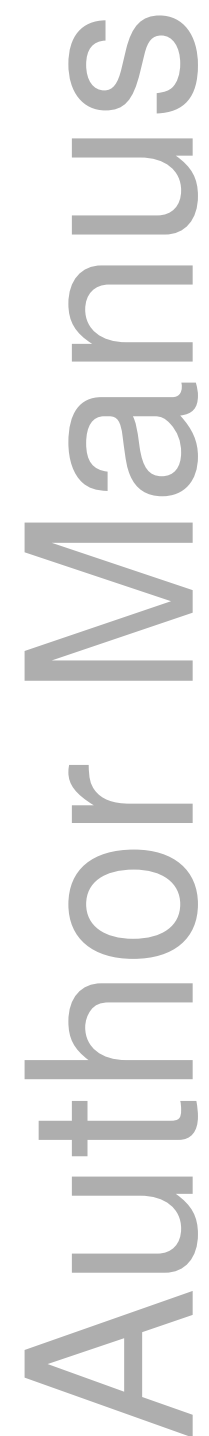


Fig 1: Flow diagram of studies selected for inclusion

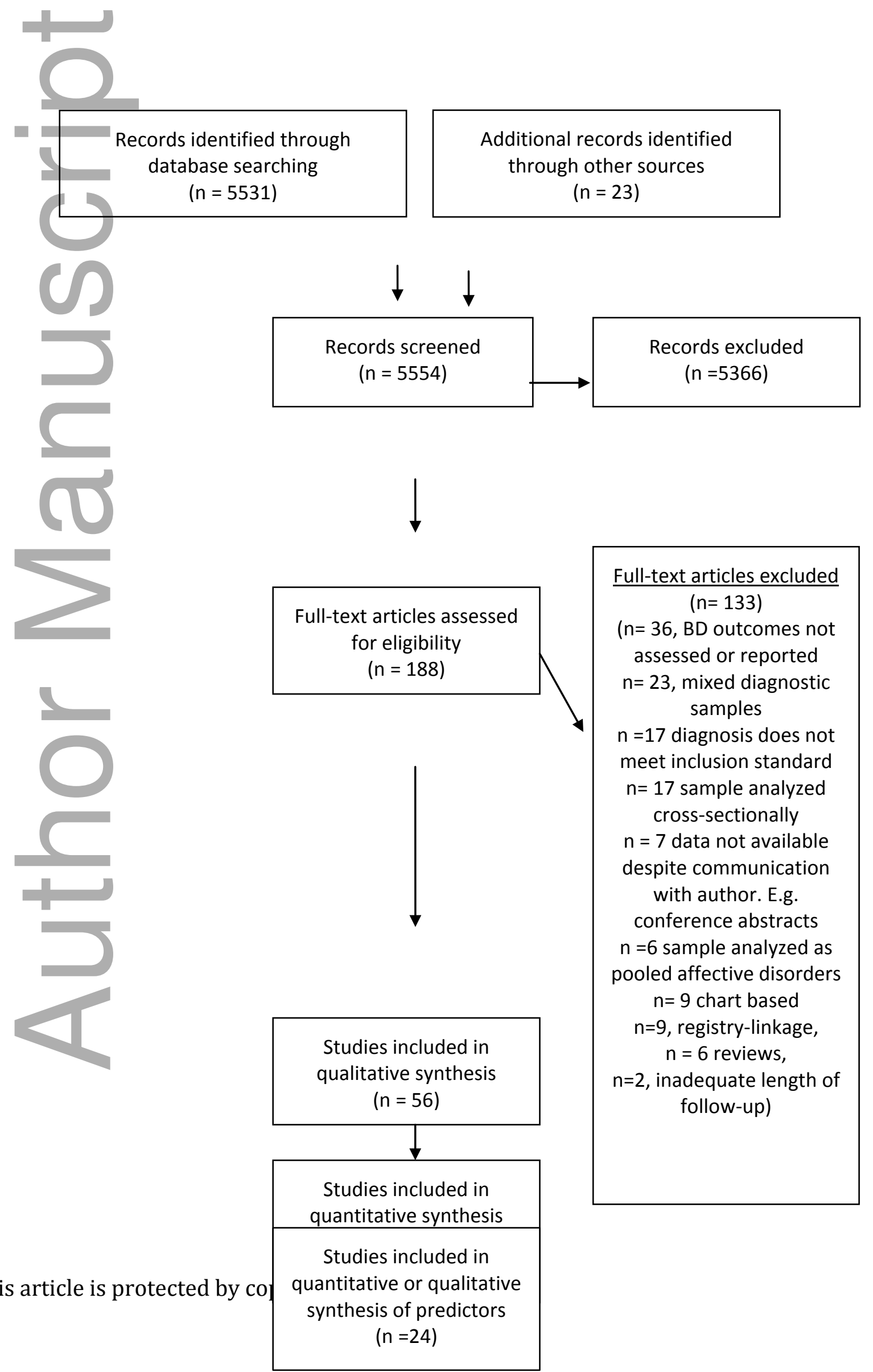




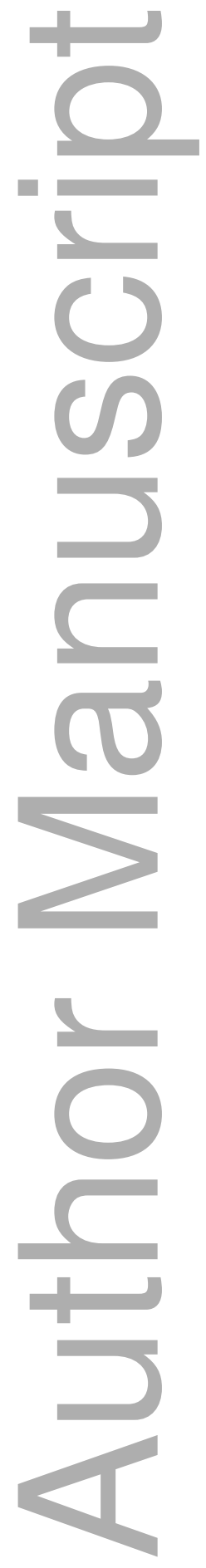

This article is protected by copyright. All rights reserved 


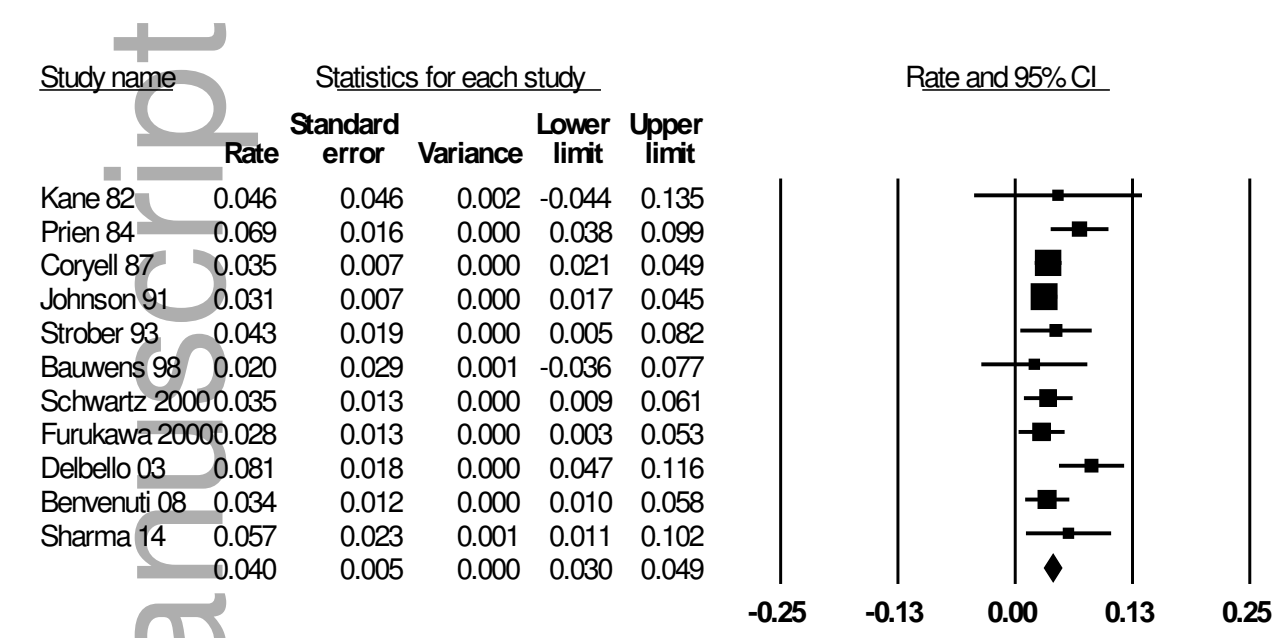

Fig 2: Incidence of BD in the first 2 years of follow-up in random effects meta-analysis ( $\mathrm{n}=11)$. Sensitivity analysis excluding Gan 11 due to high statistical $\left(I^{2}=49.5 \%\right)$ and clinical heterogeneity. Heterogeneity for current analysis $\left(\mathrm{Q}=10.46, \mathrm{df}=10, \mathrm{I}^{2}=4.4 \%\right)$

This article is protected by copyright. All rights reserved 


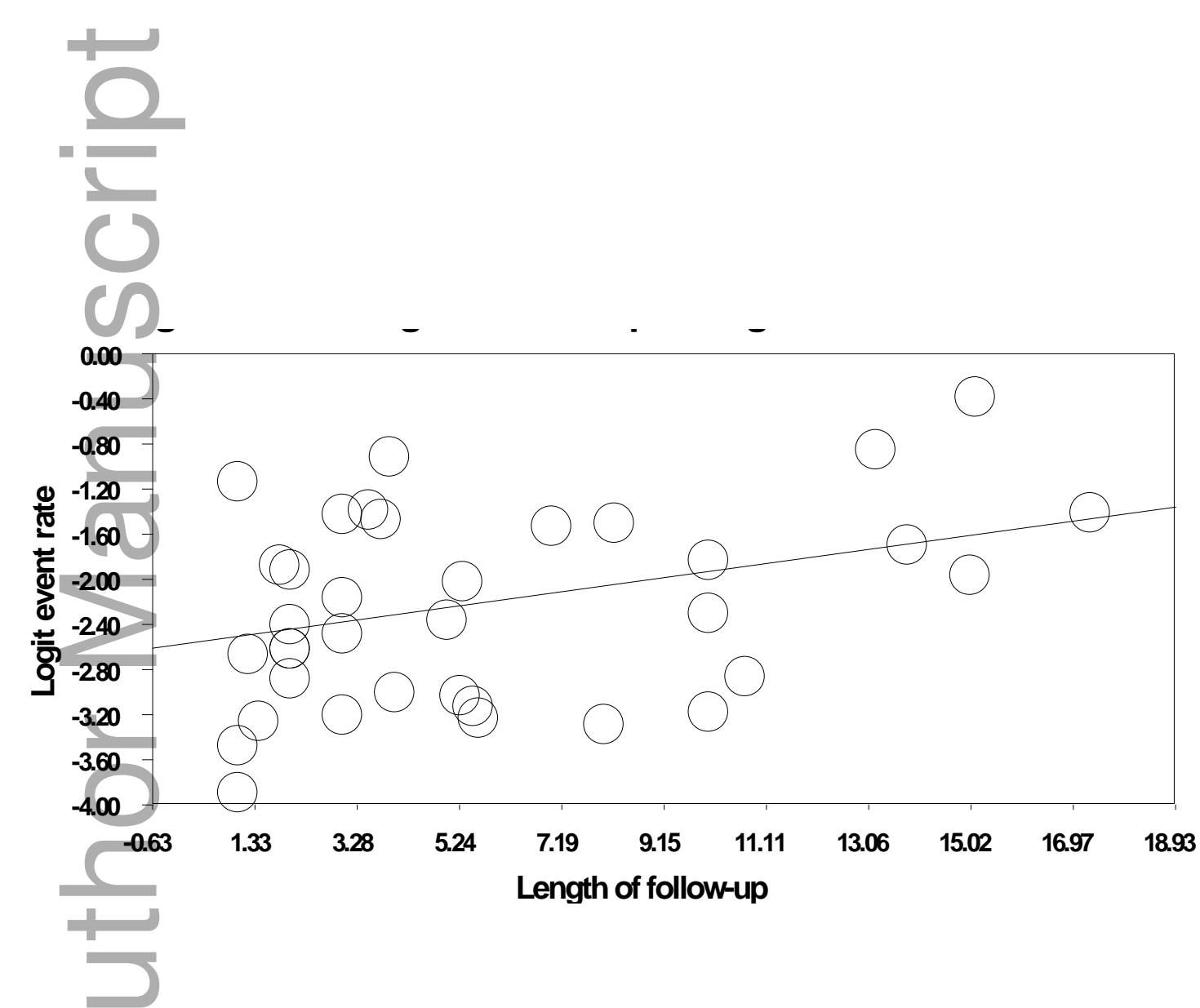

Figure 3: Metaregression of point prevalence of bipolar disorder on length of follow-up $(n=34$ independent reports Slope $0.062, \mathrm{SE}=0.03, \mathrm{p}=$ $\left.0.038, \mathrm{~T}^{2}=0.62\right)$.

This article is protected by copyright. All rights reserved 


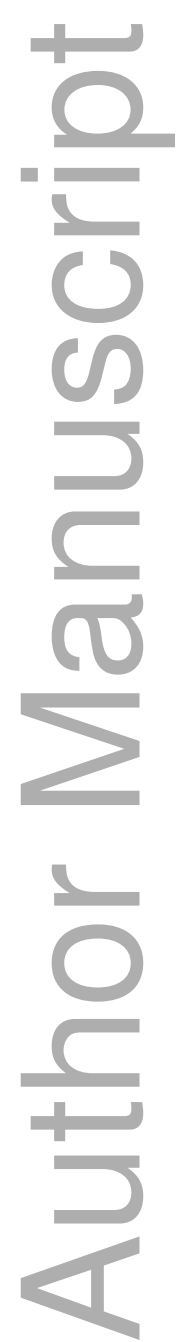

This article is protected by copyright. All rights reserved 


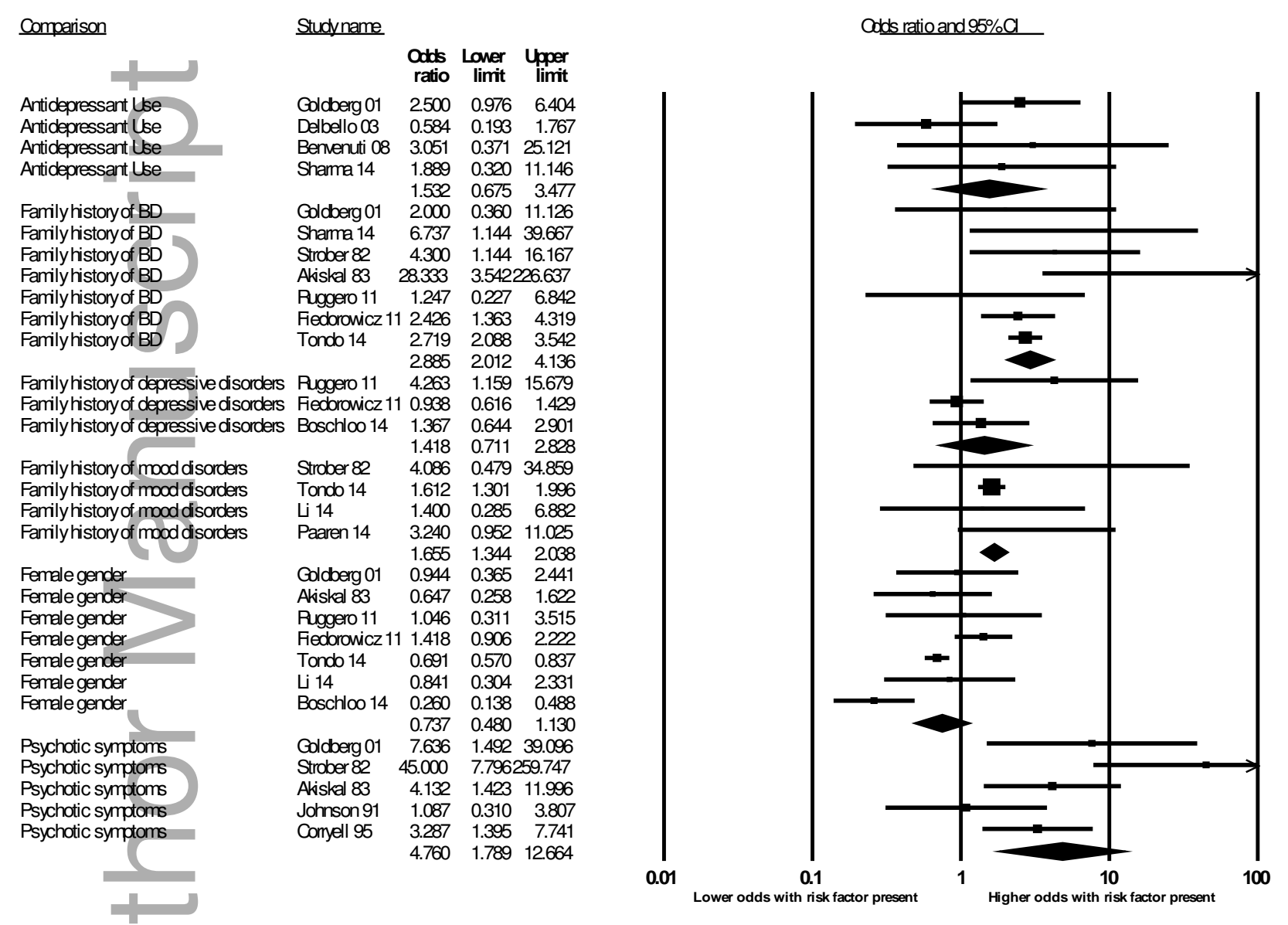

Fig 4: Categorical predictors of transition to Bipolar Disorder (BD) in random effects meta analyses

This article is protected by copyright. All rights reserved 
Note: Heterogeneity values are as follows: Antidepressant use $\left(\mathrm{Q}=2.62, \mathrm{Q} \mathrm{df}=3, \mathrm{I}^{2}=0 \%\right)$, Family history of $\mathrm{BD}\left(\mathrm{Q}=6.93, \mathrm{Q} \mathrm{df}=6, \mathrm{I}^{2}=13.4 \%\right)$, family history of mood disorders $\left(\mathrm{Q}=1.94, \mathrm{Q} \mathrm{df}=3, \mathrm{I}^{2}=0 \%\right)$, family history of depressive disorders $\left(\mathrm{Q}=2.49, \mathrm{Q} \mathrm{df}=2, \mathrm{I}^{2}=19.7 \%\right)$, female gender $\left(\mathrm{Q}=5.84, \mathrm{Q} \mathrm{df}=6, \mathrm{I}^{2}=0 \%\right)$, presence of psychotic symptoms $\left(\mathrm{Q}=5.29, \mathrm{Q} \mathrm{df}=4, \mathrm{I}^{2}=23.5 \%\right)$

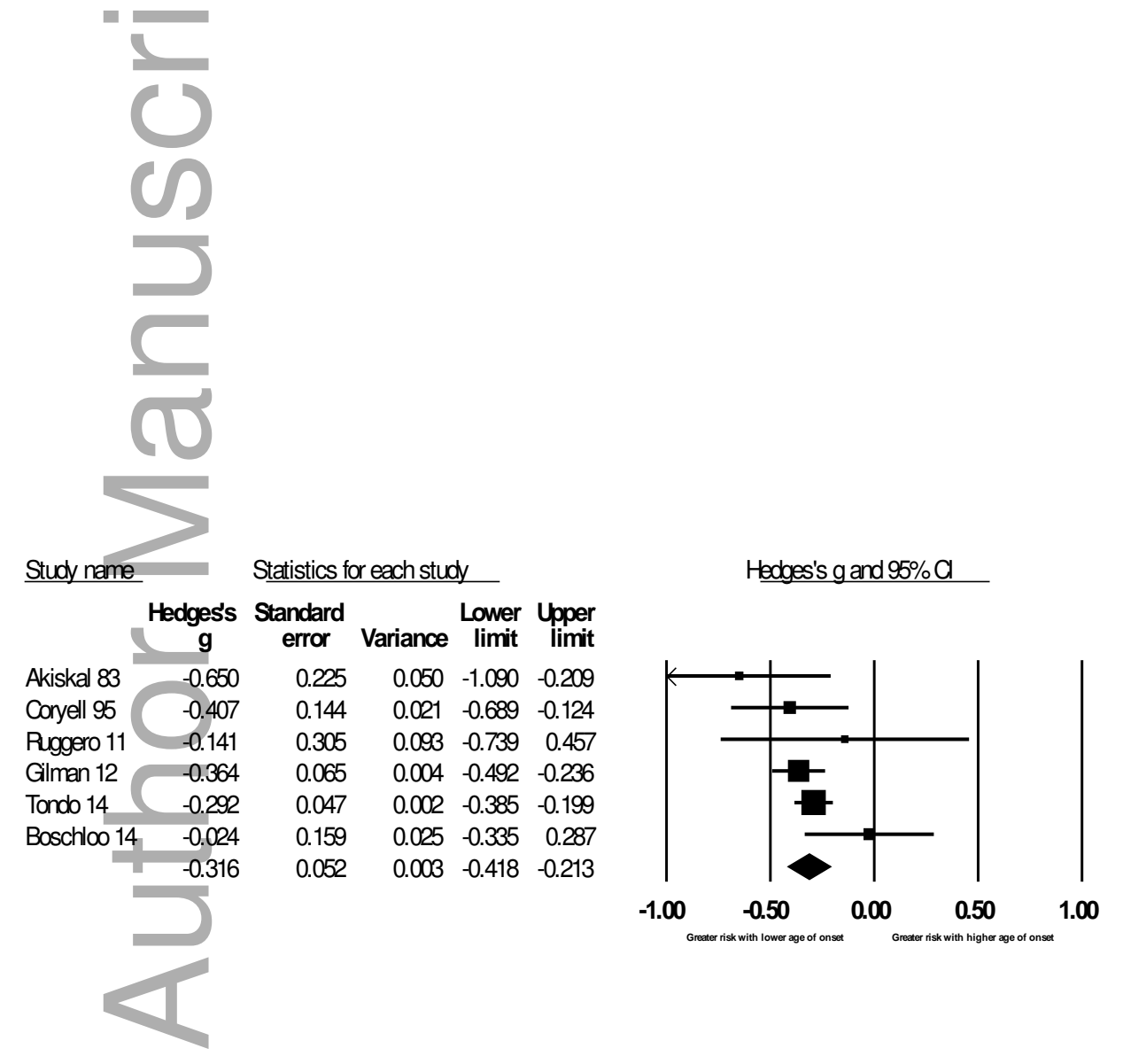

This article is protected by copyright. All rights reserved 
Fig 5: Impact of age of onset on transition to BD in random effects analysis (Hedges $\left.\mathrm{g}=-0.33, S E=0.05, Q=5.90, d f=5, I^{2}=15.3 \%\right)$ )

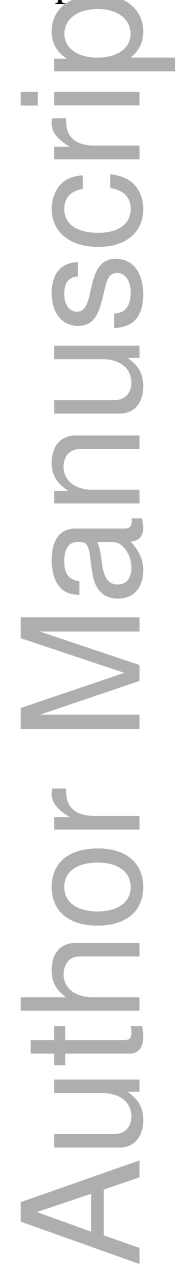

This article is protected by copyright. All rights reserved 


\section{University Library}

\section{- M M N E R VA A gateway to Melbourne's research publications}

Minerva Access is the Institutional Repository of The University of Melbourne

Author/s:

Ratheesh, A;Davey, C;Hetrick, S;Alvarez-Jimenez, M;Voutier, C;Bechdolf, A;McGorry,

PD;Scott, J;Berk, M;Cotton, SM

Title:

A systematic review and meta-analysis of prospective transition from major depression to bipolar disorder

Date:

2017-04-01

Citation:

Ratheesh, A., Davey, C., Hetrick, S., Alvarez-Jimenez, M., Voutier, C., Bechdolf, A., McGorry, P. D., Scott, J., Berk, M. \& Cotton, S. M. (2017). A systematic review and meta-analysis of prospective transition from major depression to bipolar disorder. ACTA PSYCHIATRICA SCANDINAVICA, 135 (4), pp.273-284. https://doi.org/10.1111/acps.12686.

Persistent Link:

http://hdl.handle.net/11343/292330 